\title{
Synergistic Effects of a Sulfate-Reducing Bacteria and an Applied Stress on the Corrosion Behavior of 17-4 PH Stainless Steel After Different Heat Treatments
}

\author{
Ming Wu ${ }^{1, *}$, Zhihao Zhao ${ }^{1}$, Xu Wang ${ }^{2,3, *}$, J. C. Huang ${ }^{3}$, Xinyi Liu $^{2}$ \\ ${ }^{1}$ College of Petroleum Engineering, Liaoning Shihua University, Fushun, Liaoning, 113001, China \\ ${ }^{2}$ School of Mechanical Engineering, Liaoning Shihua University, Fushun, Liaoning 113001, China \\ ${ }^{3}$ Department of Materials Science and Engineering, Hong Kong Institute for Advanced Study, City \\ University of Hong Kong, Kowloon, Hong Kong \\ *E-mail: wuming0413@163.com, wangxu@lnpu.edu.cn
}

doi: $10.20964 / 2020.01 .31$

Received: 16 August 2019 / Accepted: 18 October 2019 / Published: 30 November 2019

The individual and synergistic effects of sulfate-reducing bacteria (SRB) and an applied stress on the corrosion behavior of 17-4 precipitation-hardened ( $\mathrm{PH})$ stainless steel in sterile and SRB-inoculated solutions were investigated by electrochemical impedance spectroscopy and fractographic observation. Different heat treatments were applied to the 17-4 PH stainless steel, including single-stage aging, double-stage aging, and an intermediate treatment. The microstructures of the 17-4 PH stainless steels were mainly composed of lath martensite. However, the samples subjected to an intermediate treatment showed improved toughness as a result of the uniform and fine lath martensite. Among the samples considered in this study, the double-stage aged samples exhibited the highest yield strength and maximum stress corrosion cracking (SCC) susceptibility $\left(I_{\mathrm{scc}}\right)$ of $43.2 \%$ in the sterile solution. In the SRB-inoculated solution, the impedance values of all samples were reduced, and the production of harmful metabolites, such as $\mathrm{FeS}$ and $\mathrm{H}_{2} \mathrm{~S}$, occurred, indicating that SRB promoted corrosion of the stainless steel. The double-stage aged samples were the most sensitive to the SRB among the samples considered herein, where the $I_{\mathrm{scc}}$ was $52.8 \%$. The SCC mechanism for single-stage aged and intermediate-treated samples was anodic dissolution (AD), and that for the double-stage aged samples was hydrogen induced cracking (HIC).

Keywords: 17-4 PH stainless steel, applied stress, sulfate-reducing bacteria, stress corrosion cracking

\section{$\underline{\text { FULL TEXT }}$}

(C) 2020 The Authors. Published by ESG (www.electrochemsci.org). This article is an open access article distributed under the terms and conditions of the Creative Commons Attribution license (http://creativecommons.org/licenses/by/4.0/). 